\title{
ROMANIAN HIGHER EDUCATION REFORM AND ADAPTATION BETWEEN THE REQUIREMENTS OF THE KNOWLEDGE SOCIETY
}

\author{
Viorica Ştefan ${ }^{l}$, \\ Mariana Chivu ${ }^{2}$
}

\begin{abstract}
In today's society, characterized by a continuous process of globalization and knowledge-based economy, intellectual property is the central resource that creates the real value in all sectors of economic life. In this context, higher education's mission is to provide the highest quality standard representing a main actor in providing highly skilled workforce and creating knowledge. Thus, we say that to meet the new challenges that universities is need to go through the stages of a process of reform and adaptation, in line with the Lisbon Strategy.

Consequently, our approach is to put in the foreground the need to create a new system of higher education to meet the new demands of society.
\end{abstract}

Keywords: higher education quality reform, knowledge management education.

JEL codes: $I 23$

\section{Introduction}

The concerns of the society and economy of the XXI ${ }^{\text {th }}$ century is moving towards creating a Europe of knowledge where people would have the ability to live and turn into a competitive knowledge-based environment. In this context, education, stated that the primary factor in the complex and enduring creation, the development of knowledge-based society, the main objective of the European Union launched the Lisbon Strategy.

Moreover, the university has, in this process, a fundamental role, a mission of prime importance in reforming the education system, to meet the current requirements of the labor market. To be and to remain competitive, the universities in Romania must be permanently connected to the changing of the requirements.

In the continuous process of reform and adaptation, they must establish a set of objectives, depending on the realization that the institutions can be evaluated as efficient and competitive in the knowledge society: education quality, research excellence, capacity to produce knowledge in the highest standards, cultivate innovation and creativity in the teaching - learning process and research, boosting performance, competitiveness at national, european and world wide level and never less a strong labor market addressability.

To achieve these goals the universities need a very good management, the promotion of a student-centered learning and results-oriented, the development of culture of quality, success and social efficiency.

Thus, the education reform, as a continuous process that constantly challenges, launches higher education, Romanian universities are found at this time in the state of preparedness to participate in the Europe of knowledge and research and, moreover, prepare their own future beyond 2010, in a world of fierce competition, internationalization and globalization, in which more than ever, "knowledge is the power" as the philosopher Francis Bacon said.

\footnotetext{
${ }^{1}$ Valahia University of Targoviste, Romania, e-mail: vio_stef69@yahoo.com.

${ }^{2}$ Valahia University of Targoviste, Romania,e-mail: mariana.chivu @ medu.edu.ro.
} 
Since the reorganization of modern society involves and changes regarding teaching the ways of evaluating and assessing the outcomes the education, the relationship between students and teachers but also the nature of knowledge and principles transmitted, education and investment in education implied should constitute the right components to ensure a long-term human development.

Achieving high performance means higher education institutions reached or exceeded targets of increasing the quality, productivity, customer satisfaction and not least the acquisition of competitive advantage.

\section{The situation of higher education in Romania at the beginning of XXI century}

To highlight the current state of university education in Romania, as a pillar of society and knowledge economy, we chose to do a comparative analysis through structural indicators, to what exists in the EU-27:

- the number of graduates;

- public participation in the training programs;

- expenditure on education in GDP

- long term unemployment's rate influenced by higher education.

1. What supports Romania's transition to the knowledge-based economy is our intellectual capital appreciation, primarily reflected by the increasing number of graduates.

According to our national statistics, we see that in 2007/2008 arround 232900 students have graduated, double compared to the 2005/2006 academic year, when 112,200 students have graduated (Romania in Figures, 2009).

There is an increasing demand for higher education, a phenomenon faced by all countries. A demand for new school places increases continuously, more and more students, of diverse types and ages enroll for higher education to be trained in various forms in a growing number of areas and in the modern educational programs. The phenomenon is due to the full democratization of growing companies.

Also, the structure of groups of specialization in higher education students enrolled in academic year 2008/2009, reflecting the many students choosing to study in Romania especially in economics specialties $31.6 \%$, followed by academic and pedagogical with a $26.4 \%$ share, topping the least technical specialties with a rate of $21.2 \%$. And higher education in the private sector, the largest weight recorded for students who study economics with a share of $43.6 \%$. From this, we conclude that the demand for study for the technical is reduced, and because we say the current situation of national economy and hence the demand on the labor market.

In respect of the persons employed, we can say that, in 2006, $13.45 \%$ of them were college graduates, while in 2008 there was a lower percentage with 8\%, compared to an average of $20 \%$ in Europe and $30 \%$ in the U.S., according to data provided by ARACIS in 2009, the Quality Barometer.

In 2010, people with higher education were at a rate of $84.7 \%$ among the employed population, those with secondary education $63.6 \%$ and those with low educational level of $45.1 \%$, source INS Romania.

2. Another indicator is the analysis of training participation, rate of population between 25-64 years.

According to the statistics, this indicator for Romania has increased in recent years, this was achieved in 2008, the threshold of $1.5 \%$ versus $0.9 \%$ in 2000 , although for workplace training according to Eurostat, Romanian companies invest on average only $0.5 \%$ of the human resource training courses, which is the lowest among countries in the region (Czech Republic 1.9\%, Hungary $12 \%$, the EU average being 1.15\%). (Tab.no.1.) 
Table no.1.

Training participation rate of the population aged between 25-64 years (period 1997-2008)

\begin{tabular}{|l|c|c|c|c|c|c|c|c|c|}
\hline & $\mathbf{1 9 9 7}$ & $\mathbf{1 9 9 8}$ & $\mathbf{1 9 9 9}$ & $\mathbf{2 0 0 0}$ & $\mathbf{2 0 0 1}$ & $\mathbf{2 0 0 2}$ & $\mathbf{2 0 0 4}$ & $\mathbf{2 0 0 6}$ & $\mathbf{2 0 0 8}$ \\
\hline UK & - & - & 19,2 & 21,1 & 21,7 & 22,3 & 29 & 26,7 & 19,9 \\
\hline EU-15 & $\mathbf{5 , 8}$ & - & $\mathbf{8 , 2}$ & $\mathbf{8 , 5}$ & $\mathbf{8 , 4}$ & $\mathbf{8 , 5}$ & $\mathbf{1 0 , 7}$ & $\mathbf{1 1 , 2}$ & $\mathbf{1 0 , 9}$ \\
\hline Spain & 4,5 & 4,3 & 5,1 & 5,1 & 4,9 & 5,0 & 4,7 & 10,4 & 10,4 \\
\hline Poland & - & - & - & - & 4,8 & 4,3 & 5 & 4,7 & 4,7 \\
\hline Hungary & 2,99 & 3,3 & 2,9 & 3,1 & 3,0 & 3,3 & 4 & 3,8 & 3,1 \\
\hline Romania & 0,9 & 1,0 & 0,8 & 0,9 & 1,1 & 1,1 & 1,4 & 1,3 & 1,5 \\
\hline
\end{tabular}

Source: EUROSTAT (Romanian Statistical Review nr.2/2010)

Consequently, we can say that, in the knowledge society, higher education involves developing the skills of human resources in accordance with the requirements of $\mathrm{XXI}^{\text {th }}$ century. You also need to realize that training in the knowledge society must mean:

- technology;

- identify ways in which students and teachers can use technology to research, communication and collaboration in the learning process;

- providing learning opportunities through active participation in this process;

- facilitating educational management strategy that focuses on student learning and encourage higher-order thinking;

- colaboration to solve the task through effective communication and participation in problem solving unit.

3. The share of GDP's spent on education is one of the most important indicators for the analysis of higher education.

If, until 1990 the main source of financing public education was the Romanian higher budgetary allocation for this chapter, since 1999 the financing changes, passes it to a methodology for allocating budgetary allocations based on formula (quantitative component) based on the fundamental principle "follows students resources" and in 2002 the quality component, permanently updated (Gh.Dincă, Radu Damian, 1997). Thus, one can see (Table no.2) that things have changed, but not too much, this segment is still insufficient funding, higher education in Romania in 2007 benefiting from a share of funds allocated for core funding of total GDP only $0.39 \%$ compared to $0.34 \%$ in 2000 .

Evolution core funding period 1998-2007

Table no.2.

\begin{tabular}{|l|l|l|l|l|l|l|l|l|l|l|}
\hline & $\mathbf{1 9 9 8}$ & $\mathbf{1 9 9 9}$ & $\mathbf{2 0 0 0}$ & $\mathbf{2 0 0 1}$ & $\mathbf{2 0 0 2}$ & $\mathbf{2 0 0 3}$ & $\mathbf{2 0 0 4}$ & $\mathbf{2 0 0 5}$ & $\mathbf{2 0 0 6}$ & $\mathbf{2 0 0 7}$ \\
\hline $\begin{array}{l}\text { Total basin } \\
\text { financing }\end{array}$ & 137 & 107 & 135 & 146 & 153 & 169 & 209 & 287 & 332 & 446 \\
\hline $\begin{array}{l}\text { Percentage } \\
\text { FB } \\
\text { Out of PIB }\end{array}$ & $\begin{array}{l}0,37 \\
\%\end{array}$ & $\begin{array}{l}0,32 \\
\%\end{array}$ & $\begin{array}{l}0,34 \\
\%\end{array}$ & $\begin{array}{l}0,33 \\
\%\end{array}$ & $\begin{array}{l}0,32 \\
\%\end{array}$ & $0,32 \%$ & $0,34 \%$ & $0,36 \%$ & $0,34 \%$ & $0,39 \%$ \\
\hline
\end{tabular}

Source: CNCSIS

Also, according to the studies of outlining the development of core funding allocated to Romanian universities, in 2007, they have received 446 million euros compared with 135 million Euro in 2000, which leads us to conclude that it is still necessary a substantial increase in funding for our higher education as well as, to integrate fully into the European Higher Education Area and to meet quality requirements and performance. 
Whatever the mission statement or definition of an institution of higher education products, its main purpose is to serve the society. Commonly accepted the dimensions of this mission are: education, scientific research, direct assistance and services granted to the university community (students and their staff). To achieve these dimensions at an appropriate university must have the capability and resources necessary given, adequate internal organization mission and objectives.

In this context, drawing on resources and their proper use through effective and efficient organization becomes a priority for the university.

The funding aims to support with adequate financial resources to higher education institutions and systems so that, by their performance in generating and disseminating knowledge, they will become a factor of economic growth, social welfare and increase the prestige and international recognition of the Romanian universities.

\section{Increased interest in higher education is determined by the existence of a higher degree of labor market absorption of highly skilled labor and a lower risk of unemployment for university graduates.}

According to Eurostat, in 2009 youth unemployment rate reached $19.6 \%$, a value similar to Portugal, Romania occupied the 13th position in the EU Member States.

The overall EU unemployment rate among young people rose in the first quarter of 2009 to $18.3 \%$ from $14.6 \%$ in the same period in 2008 , the highest youth unemployment rate was registered in Spain, 33, 6\%, and lowest in the Netherlands, $6 \%$.

For graduates of higher education in Romania we've registered the unemployment rate at the end of 2008, a rather high value of 7.9\% (data of the National Employment Work-NEA), given that there were two generations of graduates, with the implementation of Bologna, compared with 1991 when the rate was $2.3 \%$.

Also, the employment rate of working population aged between 20-64 years was 58.8\% in 2010, the highest occupancy rate recorded among higher education graduates, according to information provided by NIS ( National Institute of Statistics).

Employment rate of $58.8 \%$ in Romania remains modest compared with the Lisbon Agenda goal of $70 \%$ and is even below the EU average (60.2\%). The objective of increasing employment rates is of paramount importance for Romania, the most important objective of Europe 2020.

Despite the failure of individual EU countries to achieve the objective of $70 \%$ employment rate, the European Union allowed the member countries to establish national objectives, so each country could outline the strategy according to its particular situation and so it may reach by 2020 an employment rate de75\%. (Figure no.1).

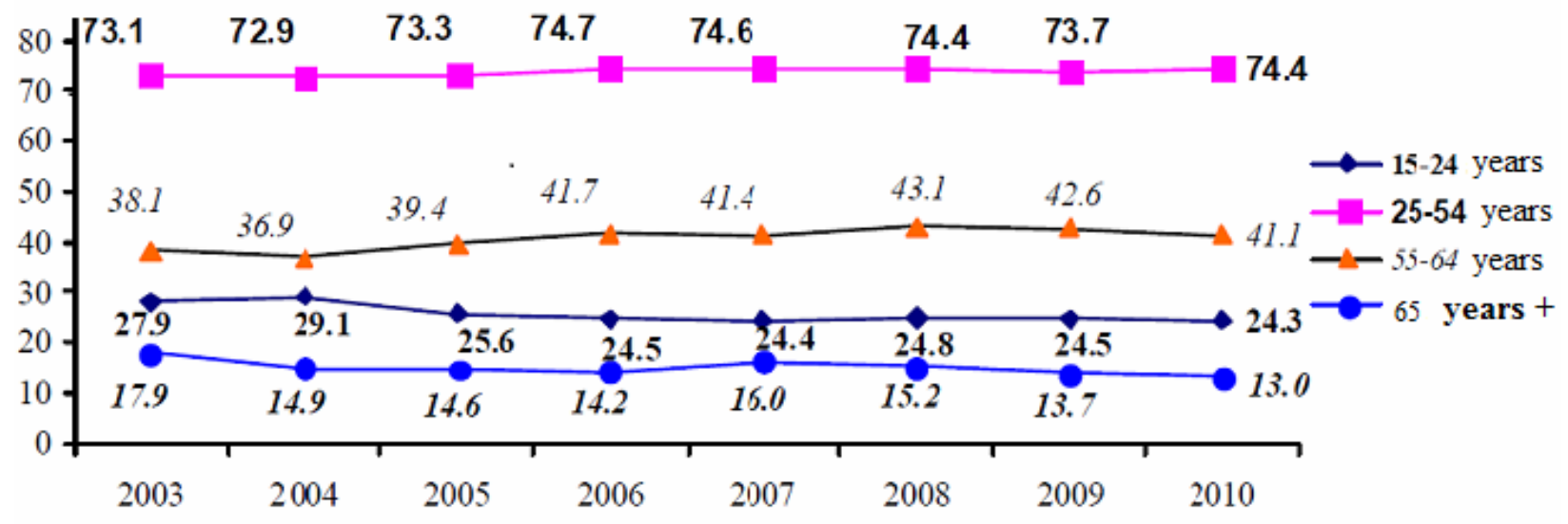

Fig.no.1. - Employment rate of population by age group 
The highest employment rate for working people has been among higher education graduates $82.4 \%$, according to NIS ( National Institute of Statistics).

It is noted that, as education decreases, decreases and employment. In Romania, employment according to education level recorded in 2010 (Figure no.2) level of $80 \%$ for those with higher education and only $42.0 \%$ for those with low education level.

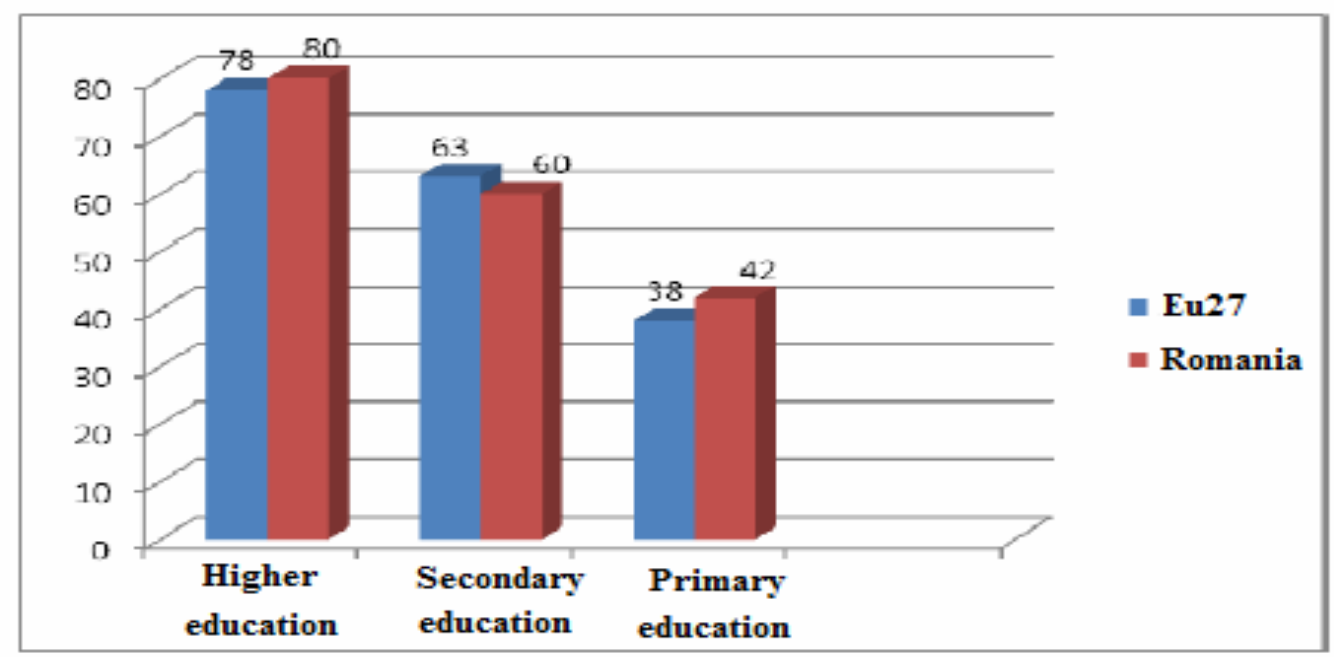

Fig.no. 2. - Employment rate (\%) by education level (EU and Romania, 2010). Source: Eurostat, 2011

From this point of view, we say that it is necessary for our universities to influence and shape the employment and development of society, not only to respond to the labor market demand.

Consequently, we can say that the role and responsibilities should assume higher education systems aimed to help and improve the employment opportunities for graduates, which is an important component of quality management in higher education. We believe that higher education raises the chances of the employment. Hence, it is important to identify mechanisms that contribute to increased employment opportunities for graduates. Although most data show that while the quality of the education system and hence the preparation of graduates has decreased, we believe that higher education graduates develop skills that still supports the occupation.

By reference to the quality of management system, our higher education requires that educational institutions insists on knowledge in each specializations, and some specific job requirements for the program of the study that prepares students. In this respect, for each program of study is necessary to know for what jobs the graduates are prepared, which are the most common jobs held by graduates after completion of studies, which are the main skills needed for the performance of an activity on the respective stations.

These lines of research need to be implemented at each institution of higher education, so that each area of the study identify the main needs of the employing companies, providing a landmark development in the curriculum.

The analysis of these indicators leads us to conclude that Romania needs to create a new system of higher education, which first must receive substantial funding and a legislative and administrative framework for modern, efficient and competitive environment to ensure proper development and transformation in a growing system of quality education and excellence in research, creativity and innovation, performance and competitiveness in Europe. 


\section{Management education - a possible solution to link higher education requirements and current needs of society}

Current higher education in Romania has to face very complex problems among which the increase of students and universities, scientific and technological progress, which require rapid adaptation to changing requirements of its social life and the market economy. This makes the whole organization of academic activities to be increasingly more difficult based on the processes used to date, and orientation to university management appears as a natural and necessary solution.

In this context, knowledge management practice is the first condition for academic quality management, efficient, rational, creative, successful and development-oriented. It can be considered as all processes by which theoretical and methodological elements of science provided by management are operating in social practice (Nicolescu, O., (eds.) 1995).

Thus, to achieve its objectives, any university needs good management, the promotion of a student-centered learning and results-oriented, the development of culture of quality, success and social efficiency. Actions promoted under this area of intervention aimed at modernizing and restructuring higher education in an integrated approach:

- action system;

- support for providers;

- staff development;

- developing and providing higher education;

- innovative actions to improve and develop higher education.

The actions developed at the provider system implies support for the development and implementation of tools, standards and methodologies, especially for skills development, quality assurance, planning and management of educational offerings in higher education. Concrete actions to be undertaken within this key area of intervention will aim to provide quality university education by providing the quality and management, effective systems management and administration of higher education and university research, exchange of best practices, etc. To meet the requirements of the knowledge society, it will focus on actions aimed at developing postgraduate education offers (in support of acquiring new knowledge and increase skill levels of human capital) and on actions to ensure solid foundations for increasing the competitiveness of human capital in education and training (eg masters, doctorate).

All these actions occur in a competitive environment, essential to the success or failure of the university, its contribution to realizing results mainly through innovation or successful implementation of a culture which effectively link the organization. Faced with competition, the university must develop a strategy to enable it to find a favorable position, where competition takes place mainly. Thus, the strategy aims to achieve a profitable and sustainable position in the midst of forces, that define the competitive sector (Michael Porter, 1999).

To increase the responsiveness of higher education to changes in society, to foster economic competitiveness and innovation and to promote entrepreneurial skills and competencies that universities need to interact with the business community and research and development sector, particularly, through the development and strengthen partnerships. The relationship between universities and economic environment is a strategic element for future mission of all educational institutions, through a reformulation of policies in relation to each other innovative centers of economic development regions of Romania.

On this partnership between universities and public-private sector through "public clusters," says that in Romania, because of poor cooperation between companies and between public and private sectors, we are faced with issues concerning the creation and promotion. In this respect, the Romanian government tried through public policy, to give rise to what we call "public clusters," which, by law, have the status of industrial, scientific and technological parks. By their very nature, these science parks should promote research and innovation by working directly with academia. 
And in this respect Romania has a low level, which requires creating a large number of organizations and cluster achieving convergence with the EU average, an effort for a period exceeding 50 years, the range can be reduced if education becomes a national priority.

\section{The role of higher education in Romania in society and knowledge economy}

Studies and data on the contribution of education and training to promote economic growth, shows that higher education is the most important factor contributing to higher levels of education. As I have said "Knowledge is power and profitability." This new concept that we promote is achieved because the university:

- current research produces knowledge;

- knowledge is transmitted through education and training;

- disseminates planetary knowledge through new communications technologies and information;

- knowledge is applied in technological innovation.

The term knowledge society - knowledge society derived from - redefining higher education issues as the economic aspects of quality of life are related to long-term evolution of not only business but also education and knowledge capitalization. Regarding the evolution of the national model of education, research and development, it is provided by European Union bodies. Romanian higher education integration into international flows is based on the Lisbon Declaration (2000) and the Barcelona Declaration (2002), by the European Union has proposed to develop within a decade the most competitive knowledge-based economy. These documents include measures that show what are the main lines of action-vectors of the knowledge economy: information society, education and research (on three priority areas: employment, increasing connectivity in Europe and knowledge).

Higher education is thus a major direct contribution to the formation of human resources. Using your own capacity for innovation and reform, higher education will become a lever to give impulse to the Romanian society in connection to social and economic developments that influence them and direct them. Concrete actions that will take place in universities, in order to develop human resources, are:

- specializations adaptation to the needs of the labor market;

- development of university research;

- encouraging the return flow of young people studying abroad;

- strengthening international partnerships;

- stimulate new forms of university, and distance learning.

Integration of scientific activities are major target of the EU international cooperation in the scientific.

Currently, the university education system in Romania and every institution of higher education reform process is triggered as a result of the Bologna Process and the necessity imposed by the competition to achieve an efficient economy under globalization accelerate development at all levels of society information. Academic reform in Romania is perceived as a dynamic process of permanent adaptation to the realities of changing economic and social. The particularity of education reform as a continuous process claims outstanding challenge at higher education institutions, national systems, challenge the direct and permanent internal quality assurance processes, the adaptability of curricula and structures, strategy and managerial competence, teacher accountability, student participation in decision making, promoting creativity and innovation in scientific research, addressability to the labor market. This reform can be achieved only within a coherent framework, built on a clear strategy for the mission, purpose and objectives of the education system. 


\section{Conclusions and Proposals}

- Investment in human capital significantly influence the economic and social development of the country so that we cannot build in Romania a knowledge economy and society without taking a real social scale of values that involves education and training throughout life.

- The current developments in science and technology universities are the main agents of the promotion of knowledge and creativity in rural socio-economic insertion. They are thus potential engines of economic development and cultural change in industrial organizations. From this point of view a judicious allocation of financial resources leads to a significant increase in performance

- The need for partnerships between academic institutions and businesses must prevail in the knowledge society, and managerial processes to establish the objective formation of highly demanded skills in the labor market because, on the economic dimension, creativity, knowledge and expertise provided to organizations industrial by universities has a direct impact on their capability to generate and / or integrate new technology innovation. Thus, the attractiveness of the market is directly influenced by the products, services and capital of these organizations and thus to increase the national economy, general welfare of the nation.

- To achieve high performance results, organizations must have the capability to manage processes established as the main problems of analysis of organization development, personal development and improve performance. Development and performance improvement is possible not only in the understanding of what has been done but also on performance.

- Innovative objective of developing economies should be a priority for Romania, and investments to create the necessary database, represented by knowledge and technology and information skills are badly needed. Thus, strengthening cooperation between universities and research institutes, development and innovation are the basis for specialization and creating intelligent added value, contributing to the sustainable development of each entity

- Sustainable competitive advantage to obtain higher education institutions only through strategies that lead to excellent results, it is mainly accomplished through quality education and consistent with current social and economic requirements.

\section{References}

1. Dinca G., Damian R., 1997. Financing of Higher Education in Romania

2. Nicolescu O. (coord), 1995. Guide management, vol. I-II, Tehnică Publishing House, Bucharest

3. Porter M, 1999. L'Avantage concurrentiel, Paris, pp.11

4. Lisbon European Council, 2000. Presidency Conclusions, Lisbon, 23-24 March

5. European Commission, 2010. Europe 2020, Brussels

6. Romania in figures 2009, available online at www.insse.ro

7. Romanian Statistical Review, 2010, no.2

8. http://eur-lex.europa.eu/LexUriServ/LexUriServ.do?uri=COM:2009:0400: FIN: EN: DOC

9. http://ec.europa.eu/publications/booklets/move/73/ro.doc 